Original Research Paper

\title{
Study of Heat-Treated Steel and Related Applications
}

\author{
${ }^{1}$ Shu-Ping Chang, ${ }^{2}$ Ming-Chen Chen and ${ }^{1}$ Jyh-Dong Lin \\ ${ }^{1}$ Department of Civil Engineering, National Central University, Taoyuan City, Taiwan \\ ${ }^{2}$ Department of Civil Engineering, Chien Hsin University of Science and Technology, Taoyuan City, Taiwan
}

\author{
Article history \\ Received: 03-05-2015 \\ Revised: 25-05-2015 \\ Accepted: 26-08-2015 \\ Corresponding author: \\ Ming-Chen Chen \\ Department of Civil Engineering, \\ Chien Hsin University of Science \\ and Technology, Taoyuan City, \\ Taiwan \\ Email: mcchen2005@gmail.com
}

\begin{abstract}
Numerous studies conducted after the 921 earthquake in Taiwan in 1999 have reported that because heat-treated steel features relatively unstable mechanics properties, using such steel in welding, bar splicing, or as thread-cutting components in structures may result in lack of resistance to seismic activity. However, nondestructive testing methods that can be used to identify the type of steel delivered to construction sites (i.e., whether the particular steel is heat-treated steel) have not yet been developed. In this study, the materials constituting the surface and interior of heat-treated steel were determined using macroscopic or microscopic metallographic inspection; the determined materials were martensitic and ferrite-pearlite structures, respectively. The hardness levels of steel of varying thicknesses were examined using the Vickers hardness test and Leeb hardness (HL) test, after which the variance in hardness between the interior and surface of the heat-treated steel were studied. The experimental results showed that the HL test can be used to determine whether steel in concrete is heat-treated steel: Under the acceptable reliability and tolerance limits are 95 and $\pm 5 \%$, respectively. Steel with an HL value of $82 \mathrm{HL}$ or higher between the surface and the interior of the steel $(1.0 \mathrm{~mm}$ below the steel surface) can be considered a heat-treated steel. The HL method, which involves measuring the difference in hardness, is a nondestructive testing method and can be used to determine whether the steel used in existent buildings is heat-treated steel.
\end{abstract}

Keywords: Heat-Treated Steel, Leeb Hardness (HL), Nondestructive Testing

\section{Introduction}

The seismic-resistant design standards (ACI, 2008) introduced by the American Concrete Institute stipulate that the tensile region steel ratio $(\rho)$ must be equal to or lower than half of the balanced steel ratio $\left(\rho_{b}\right)\left(\rho \leq 0.5 \rho_{b}\right)$. This regulation was implemented to ensure that structures maintain their toughness. This shows that the ductility of steel is crucial to the success of seismicresistant designs.

Steel used in construction comprise hot-rolled and heat-treated steel (Chen et al., 2000a); these steel types are described as follows:

In hot-rolled steel (also called vanadium (V) steel) manufacturing processes, the desired strength is achieved using $\mathrm{V}$ or other alloys such as niobium, titanium, or manganese $(\mathrm{Mn})$. The manufacturing process involves placing scrap steel (e.g., pig iron, factory tailings and recycled scrap steel) in an electric furnace and using electrodes to create an arc; in this arc, steel is heated to $1600^{\circ} \mathrm{C}$ to melt and liquefy it and are then cast in to billets (solid state). The billets are reheated to 1100 $1200^{\circ} \mathrm{C}$ by using a reheating furnace (the billets remain in solid state) and rolled into rebar (reinforcement steel) or other products. The rebar components are adjusted by adding alloys in the aforementioned liquid state, enabling the reinforcement steel to meet the Chinese National Standard 560 (CNS 560, steel deformed and plain bars for concrete reinforcement).

In heat-treated steel (also called water quenching steel) manufacturing processes, high-pressurized water is used to cool the surface of the steel(instead of using alloys to adjust steel components)toward the end of the steel-rolling process (steel at this stage is in solid state and its temperature ranges between 800 and $900^{\circ} \mathrm{C}$ ). The quenched steel surface undergoes tempering because of residual heat, forming a martensitic organization measuring approximately 1-2 mm thick on the surface of 
the steel; ferrite-pearlite structures constitute the interior component of the steel (Chen et al., 2000a; 2000b; Reed-Hill and Abbaschian, 2003). Heat-treated steel is hard on the surface and soft in the core. The type of steel may be identified by performing macroscopic or microscopic metallographic inspections or by observing the changes in hardness.

Because heat-treated steel is cheaper to produce compared with hot-rolled steel (Reed-Hill and Abbaschian, 2003; He, 2000), it has been commonly used in domestic construction since the 1990s. Billets were imported to Taiwan and subsequently manufactured into heat-treated steel. Data of the Taiwan Steel and Iron Industries Association (TSIIA) indicate that heat-treated steel output accounted for approximately $50 \%$ of total steel output in the $1990 \mathrm{~s}$, which later increased to $70 \%$ and higher in the $2000 \mathrm{~s}$ (Reed-Hill and Abbaschian, 2003; He, 2000). According to the production statistics prepared by the Department of Statistics (Ministry of Economic Affairs, MOEA), domestic steel production peaked in 2002 (Chen, 2006) and $99 \%$ of the steel was sold domestically. Data from the TSIIA for the same year indicate that $86.35 \%$ of high-tensile steel was used in the construction industry (17.73\% of which was used for public construction). This signifies that numerous buildings currently in use were built from heat-treated steel.

Heat-treated steel is used to improve strength and lower cost from alloy usage; however, the lowered costs may be associated with disadvantages such as low steel ductility or failure to pass flexural strength tests. Studies conducted after the 921 earthquake in 1999 (Chen et al., $2000 \mathrm{a} ; 2000 \mathrm{~b}$; He, 2000) have reported that because heat-treated steel features relatively unstable properties, using such steel in welding, bar splicing, or threadcutting components in structures may result in lack of resistance to seismic activity. Therefore, several government departments have formulated regulations prohibiting the use of heat-treated steel in public construction. However, because of the high level of difficulty involved in identifying the type of steel delivered to construction sites (i.e., whether the particular steel is heat-treated steel) as well as the steel found in existing architectural structures, instances of misuse have been reported. Therefore, the objective of this study was to introduce a method that can be used for quickly identifying heat-treated steel in construction sites.

\section{Literature Review}

Preparing detailed statistics of the number of heattreated steel used domestically in Taiwan is difficult; according to the production statistics prepared by the Department of Statistics (MOEA), the annual domestic output of reinforcement steel ranges between approximately 6 and 7 million tons, 99\% of which are sold domestically. In addition, data from the TSIIA website indicate that in the $1990 \mathrm{~s}$, billets were imported from three republics of the Soviet Union to Taiwan to fabricate steel and that the average annual import was approximately 4.6 million tons. These imported billets generally demonstrated a strength level similar to that of SD280W steel and most of these billets were used to manufacture heat-treated, high-tensile strength SD420 steel by employing the water quenching method. Therefore, the overall market share of heat-treated steel was estimated to be at least $65 \%$ in the $1990 \mathrm{~s}$.

\section{Regulations on Concrete Reinforcement Steel}

Chemical composition, heat treatment and machining constitute the three primary factors influencing steel quality. When smelting steel, various alloys can be added to change steel composition and characteristics; the goal is to change the chemical properties of the steel. Regarding related regulations on concrete reinforcement steel such as the CNS, Japanese Industrial Standards (JIS) and American Society for Testing and Materials (ASTM), quality tests for reinforcement steel, steel plates and steel materials generally begin with chemical composition tests (e.g., Article 5 of CNS 560; quality regulations) followed by mechanical property tests; the only exception is Article 4 of CNS560 (which regulates shape, size and quality tolerance).Specifically, reinforcement steel is certified by verifying its composition as opposed to its physical appearance or tensile strength. The physical properties (e.g., strength and hardness) of steel are attributed to its chemical composition. In addition to iron $(\mathrm{Fe})$, numerous elements, such as, carbon (C), silicon ( $\mathrm{Si}), \mathrm{Mn}$, phosphorus (P), sulfur (S), chromium (Cr), molybdenum (Mo), nickel $(\mathrm{Ni}), \mathrm{V}$ and copper $(\mathrm{Cu})$, constitute the chemical composition of steel. To ensure the quality of "steel deformed and plain bars for concrete reinforcement," CNS560 (i.e., Table 10 and 11 of sections 5.2 and 5.3, respectively) stipulates the required values for $\mathrm{C}, \mathrm{Si}, \mathrm{Mn}, \mathrm{P}, \mathrm{S}$ and $\mathrm{C}$ equivalent. Section 5.4 presents related regulations on the mechanical properties of concrete reinforcement steel, after those on chemical composition.

Regarding regulations on "General Rules for Inspection of Steel" (in CNS 2608), Section 6.2 lists rules for analyzing elements constituting steel materials, which are listed as follows: CNS 11069 (Fe and Steelmethods for determination of C content), CNS 11013 (Fe and steel-methods for determination of Si content), CNS 11014 (methods for determination for $\mathrm{Mn}$ in $\mathrm{Fe}$ and steel), CNS 11015 (Fe and steel-methods for determination of $\mathrm{P}$ content), CNS 11165 (Fe and steelmethods for determination of $\mathrm{Cu}$ content), CNS 11167 ( $\mathrm{Fe}$ and steel-methods for determination of $\mathrm{V}$ content), 
CNS 11302 (Fe and steel-methods for determination of $\mathrm{Cr}$ content), CNS 11387 (Fe and steel-methods for determination of S content), CNS 11388 (Fe and steelmethods for determination of $\mathrm{Ni}$ content) and CNS 11389 (Fe and steel-methods for determination of molybdenum content). The chemical composition of steel can also be inspected using the "method for photoelectric emission spectra chemical analysis of $\mathrm{Fe}$ and steel" (CNS 10006) approach, in which the results must comply with the regulations listed in section 5 (quality). However, the aforementioned quantification and analysis methods generally involve using solvents such as sulfuric acid, hydrochloric acid, nitrates and aquaregia; the inspection methods are thus difficult and dangerous. In addition, the elements must be dissolved and titrated separately, which is time consuming and leads to low accuracy. Although spectroscopes operated using the "General Rules for Photoelectric Emission Spectra chemical Analysis of Fe and Steel" (CNS9706) approach can facilitate performing thorough inspections quickly and accurately, applying this method to construction sites to determine whether the steel is heat-treated steel is difficult.

Because heat-treated steel demonstrates relatively unstable mechanics properties and excessively high yield strength (Fy), using such steel in welding and bar splicing or as thread-cutting components may result in a ductility ratio $(\mathrm{Fu} / \mathrm{Fy})$ that does not conform to the legal requirement (i.e., 1.25). Therefore, in May 2000, CNS 560 was subjected to its 15 th amendment. In this amended regulation, the online heat treatment process introduced in Taiwan in recent years was considered and this regulation was compared with JIS G3112, ASTMA615 (96a), A706 (96b) and A304 to revise the regulation on the use of heat-treated steel; the regulation previously states that unless otherwise requested by the buyer, the seller decides the steel to be used. Subsequently, in the 17th amendment of CNS 560, which was promulgated in February 2005 (CNS, 2005), methods that regulated the manufacturing of heat-treated steel were proposed. However, to ensure the effectiveness of steel in resisting seismic activity, many related government departments (buyers) formulated adaptive measures according to the aforementioned regulation, restricting the use of heat-treated steel. However, despite amendments being made and stringent regulations being enforced, heat-treated steel is still in production and buildings made from heat-treated steel remain standing. Therefore, developing methods for verifying the composition of existing Reinforced Concrete (RC) buildings is imperative. However, the current problem is that the chemical property analysis method used for inspecting reinforcement steel quality can be used only for naked reinforcement that has not yet been used in construction. Once it is used to construct RC buildings, subsequent inspections become difficult; this problem continues to pose problems in the construction industry.

\section{Seismic-Resistance Requirement of RC}

The mechanical properties of steel used in construction are generally expressed in terms of "strength." The strength of a specific material indicates the ability of the material to resist external forces. The yield strength of steel is a key performance indicator used in structural designs, which is commonly expressed in the form of yield strength and ultimate strength. The strength, hardness, brittleness and stiffness of steel are influenced by their $\mathrm{C}$ content. Low $\mathrm{C}$ steel is sometimes called mild steel and normally contains $0.15-0.20 \%$ of $\mathrm{C}$. They demonstrate strong ductility and are suitable for construction projects.

No official regulations are in place for prohibiting the use of heat-treated steel; using heat-treated steel is acceptable as long as they can demonstrate the strength stipulated in the original structural design and meet the chemical composition requirements. However, to achieve the goal of seismic resistance, Civil Engineering Regulation 401-86 and ACI-318-95 (CER 401-86, 1998; ACI, 1995) require that the mechanical properties of steel must exceed the minimum requirement (e.g., $F y \leq 560 \mathrm{MPa}$ ) and that they must satisfy the following conditions:

- Yield strength (Fy) regulation: The measured steel yield strength must not exceed the standard yield strength by130 $\mathrm{MPa}$

- Ductility ratio $(\mathrm{Fu} / \mathrm{Fy})$ regulation: The ratio between the measured ultimate steel strength $(\mathrm{Fu})$ and yield strength (Fy) (i.e., the "ductility ratio"; Fu/Fy) must not be less than 1.25

- Failure sequence regulation: To prevent shear failure during structural damage, a shear capacity design should be employed

To meet the condition described in the shear capacity design, ensuring the shear-resistance ability of buildings must be the top priority. In addition, strong columns and weak beams should be employed; at the beam-column joints, the flexural strength of the columns must be greater than that of the beams by 1.2 -fold. Moreover, the shear strength (capacity) of the column at the joint must exceed the sheer force created by the maximum flexural force by 1.25 -fold; the said relationship is called the over-strength coefficient. The objective of the over-strength coefficient is to ensure that structures do not generate brittle-like shear failure. According to (Chen et al., 2000b), the average elongation of heattreated steel was $17 \%$, which is comparable to that of vanadium steel $(16.8 \%)$. However, the actual yield 
strengths (Fy) of heat-treated steel were high and the average yield strength was $560 \mathrm{MPa}$. This result indicates that more than half of the heat-treated steel failed to pass the seismic resistance requirement stated in Civil Engineering Regulation 401-86 (i.e., Fy $\leq 560$ $\mathrm{MPa}$ ). In addition, regarding the seismic-resistant design, heat-treated steel featured a relatively low ductility ratio $(\mathrm{Fu} / \mathrm{Fy})$; approximately half of the steel failed to achieve the seismic resistance requirement stated in Civil Engineering Regulation 401-86 (i.e., ductility ratio $\geq 1.25$ ). By contrast, hot-rolled steel can generally demonstrate a ductility ratio of 1.25 orhigher; the steel materials are more stable. In summary, heat-treated steel shows high variance in mechanical properties (because of the level of complexity involved in controlling various factors, such as water temperature, water volume, water current and speed of steel rolling, during the manufacturing process) and low ductility ratios, rendering them comparatively less capable of satisfying the shear capacity requirements stipulated in the shear capacity designs. In addition, heat-treated steel is associated with other problems such as being unweldable (because it mars the heat-treatment process) and incompatible with thread-cutting components (because they damage the martensitic organizations on the surface of the steel). Figure 1 shows images of the martensitic organization of heat-treated steel (left) and hot-rolled steel (right); because heat-treated steel is hard on the surface and soft in the core, when the external force or force generated by earthquakes exceeds the strength of the original structural design, the warning time following yielding is insufficient. Therefore, some studies (Chen et al., 2000b; ACI, 1995) have asserted that heat-treated steel is unsuitable for building seismic-resistant structures. However, because of the inability to obtain work completion data when performing bearing capacity analyses, evaluators are regularly required to deduce the steel material type according to their experience. The most common method employed by evaluators involves assuming the strength of the steel used in the structure. The strength was assumed to be $280 \mathrm{MPa}$ for structures built before 1986 and $420 \mathrm{MPa}$ for post-1986 structures; the validity of these values has not yet been investigated. Because of the inability to confirm whether the steel is heattreated steel by using the aforementioned analyses, evaluators cannot guarantee that the column cap possesses a sufficient over-strength coefficient. In addition, they cannot guarantee that the ductility ratio $(\mathrm{Fu} / \mathrm{Fy})$ is 1.25 or higher.

\section{Theoretical Basis}

The methods currently adopted to identify hot-rolled steel and heat-treated steel are listed as follows:

Reading the serial number printed on the steel: The steel type (i.e., hot-rolled steel or heat-treated steel) can be identified by reading the serial number printed on the steel (e.g., SD280 W, SD420 W and SD420). S, D and W represent steel, deformed and suitable for welding, respectively. A serial number of SD420 indicates that the steel is heat-treated steel. However, because the steel used in existent buildings are already buried in concrete, reading their serial numbers is impractical. Using this method to identify the steel type and steel strength is thus difficult.

Conducting metallographic tests: When the crosssection of steel is cut, inlaid, grounded, polished and etched, the martensitic organization on the surface of the steel and the ferrite material on the inside of the steel can be used to determine whether the steel is heat-treated steel. For example, the existence of two circles on the macrostructure of the steel (Fig. 1, left) indicate heat-treated steel. Similarly, delicate average grain size on the outer layer of the microstructure (observed using a microscope) and rough average grain size on the inner layer of the microstructure (Fig. 2, bottom) indicate heat-treated steel. However, obtaining a steel specimen that has been buried in the concrete without damaging structure is difficult.

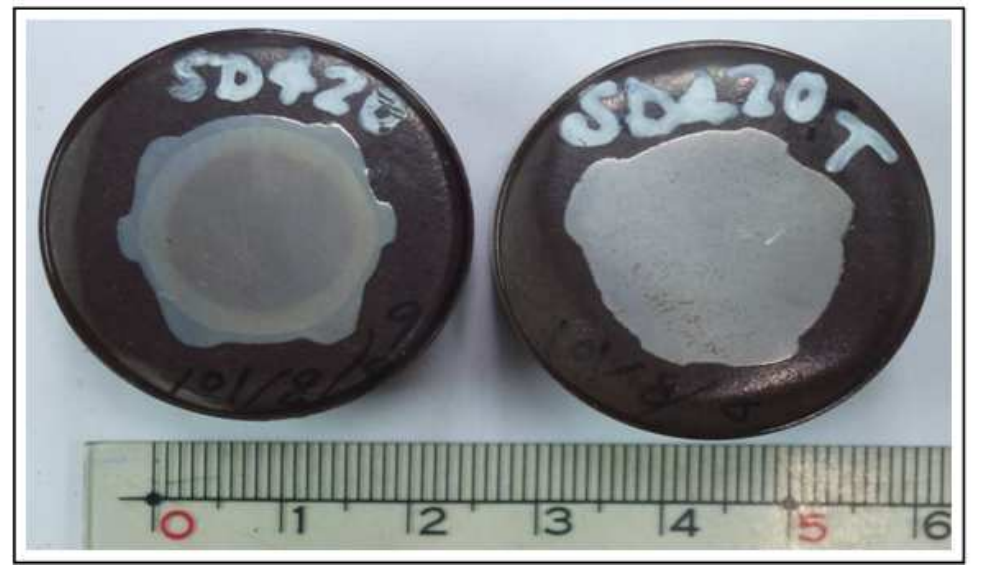

Fig. 1. Etched specimens (left: Heat-treated steel; right: Hot-rolled steel) 


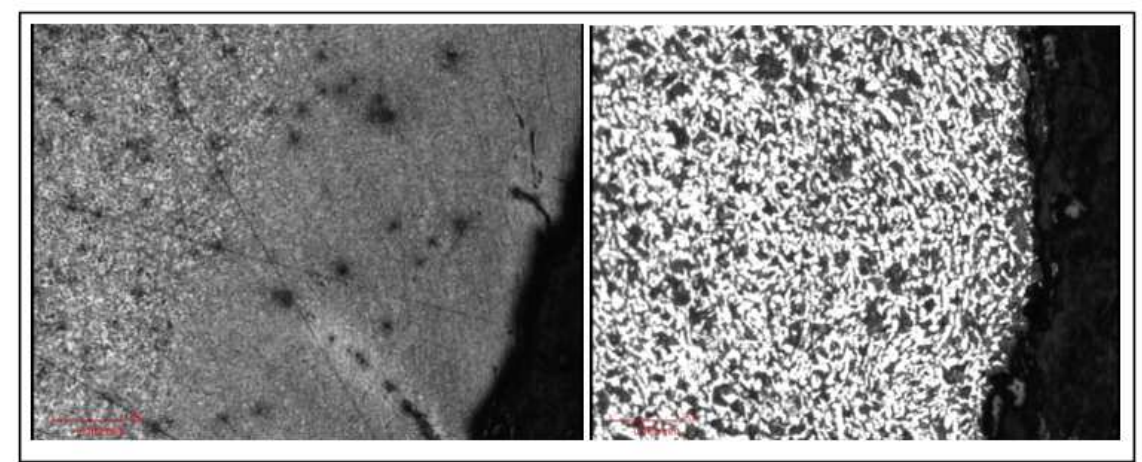

Fig. 2. Metallographic image magnified 50 times ((left) heat-treated steel and hot-rolled steel (right) with martensitic structures measuring approximately $1-2 \mathrm{~mm}$ on the edge)

\section{Conducting CNS Hardness Tests}

Common measures of hardness are listed as follows: Indentation hardness (e.g., Vickers hardness (HV)), rebound hardness (e.g., Leeb hardness (HL)), scratch hardness, wear hardness and cutting hardness. Each measure of hardness serves different purposes. The CNS 560 Appendix I now includes a section for methods in identifying steel manufactured using online heattreatment, stipulating that steel featuring a difference of more than $40 \mathrm{HV}$ between the surface and the core can be considered heat-treated steel. However, because this regulation entails obtaining a specimen, it is only applicable to laboratory tests.

To obtain the steel yield strength, the tensile test method is more commonly used. Other methods include composition analysis (using a spectroscope), test analysis of metallographic components (using an electron microscope) and material composition analysis. However, if the buildings' overall structure cannot be damaged, a nondestructive, hardness testing method may be a favorable option; this method is thus worthy of further investigation. Hypothesizing the steel type and steel strength by using hardness values is more reasonable than assuming that all steel strengths are equal to $280 \mathrm{MPa}$.

Studies (Reed-Hill and Abbaschian, 2003; CALCE, 2012; Duan et al., 2003; Guan et al., 2004; Wang and Guan, 2004) and experiments have indicated a close relationship between steel hardness and strength. This is because hardness is a measure of a material's ability to resist plastic deformation. Therefore, in general, a higher steel strength indicates a higher resistance to plastic deformation; the steel hardness value also increases. Various hardness measurement approaches serve diverse purposes and hardness tests are commonly used to control the quality of materials and products. Quality control includes assessing whether the materials in the steel are uniformly distributed and whether processing has been appropriately performed as well as determining the surface hardening status of the materials. Moreover, materials of a specific level of hardness may be required to serve a particular purpose. For example, a nondestructive testing method called the "rebound hammer test" (in which principles similar to the HL test are adopted), which is employed in civil engineering to measure the strength of concrete, can be used to estimate the strength of similar materials by comparing their various hardness values. However, currently, unlike tensile test results, hardness test results cannot be directly applied to design layouts (Duan et al., 2003; Guan et al., 2004). The reason is that hardness is influenced by several factors, such as C content, degree of wear, strength and heat-treatment situation. Nonetheless, concrete reinforcement steel demonstrates the following characteristics:

- Controlled chemical composition: According to CNS560, the chemical composition of steel must comply with specifications listed in the tables; materials with the same composition demonstrate similar mechanical properties and the correlation between hardness and strength is definite

- Low number of steel types: Contrary to the diversity of steel used for general machinery, since the 1990s, only three steel types, namely SD280W, SD420W and SD420, have been used in RC because of CNS 560 regulations. The corresponding hardness range (approximate values) of each steel type is provided in (Liu and Chen, 2012; Chang and Lin, 2013)

- Because heat-treated steel SD420 is hard on the surface and soft in the core (Chen et al., 2000a; Reed-Hill and Abbaschian, 2003; CALCE, 2012; Duan et al., 2003; Guan et al., 2004; Wang and Guan, 2004; Liu and Chen, 2012; Chang and Lin, 2013; ASME Y14.5, 2009; Gurchenko et al., 1990), it can be easily identified by examining the differences between the hardness of the surface and core of the steel 


\section{Testing Heat-Treated Steel}

Because heat-treated steel contains martensitic (a hard material) on the surface and ferrite, (a soft material) in the core, experienced personnel can identify such steel when grinding them. From the civil engineering (macroscopic) perspective, steel is homogeneous and isotropic and must satisfy only general requirements during steel hardness tests, such as being firmly inlaid, featuring polished steel surface and having test points away from the edges. Identical results should be produced regardless of the direction of the test.

In the current study, the macroscopic and microscopic examinations on the composition of steel were conducted using the metallographic test method and various hardness experiments were conducted to inspect the hardness of heat-treated steel. The instruments employed included an HV tester and an HL tester. The HV tester, also called the "micro hardness tester," identifies hardness through indentation. Because the test is performed using a microscope, this tester features a high precision level. Conversely, the HL tester is a nondestructive testing device that determines hardness via rebounds; it can also be directly used in construction sites. The literature and related regulations (Reed-Hill and Abbaschian, 2003; CALCE, 2012; Gurchenko et al., 1990) have indicated that various types of hardness test results can be converted to and from each other except for the HV test results, which can be used only in laboratories.

To examine the hardness of the steel specimens, this study employed a Vickers hardness tester (MVK-II, Akashi, Japan) that features microscopes capable of providing various magnification levels and a Phase-II Leeb Hardness Tester (USA) that conforms to ASTM A956-06. The testing procedure is explained as follows:

\section{Obtain Heat-Treated Steel}

We obtained three heat-treated steel samples with known strength (i.e., $\mathrm{Fy}_{1}=420 \mathrm{MPa}, \mathrm{Fy}_{2}=516 \mathrm{MPa}$ and $\mathrm{Fy}_{3}=$ unnoticeable; with corresponding $\mathrm{Fu}_{1}=620 \mathrm{MPa}, \mathrm{Fu}_{2}$
$=648 \mathrm{MPa}$ and $\left.\mathrm{Fu}_{3}=540 \mathrm{MPa}\right)$. The ductility ratios of the three steel samples were $(\mathrm{Fu} / \mathrm{Fy})_{1}=1.476,(\mathrm{Fu} / \mathrm{Fy})_{2}=1.255$ $\operatorname{and}(\mathrm{Fu} / \mathrm{Fy})_{3}=0$. These results show the considerable variance in the ductility ratio among the heat-treated steel.

\section{Confirm the Martensitic Organization Thickness of Steel by using Metallography}

We obtained various reinforcement steel specimens in this test. The specimens' macrostructure (Fig. 1) was observed by inlaying, grinding and polishing the specimen and wiping it with $5 \%$ nitrate-alcohol solution. By contrast, the specimens' microstructure was observed by magnifying the metallographic image 50 times (Fig. 2). The images indicated that the hotrolled steel contained homogeneous materials (pearliteferrite structures) (Fig. 2, top), whereas the heat-treated steel contained a dense, 1-2-mm-wide martensitic structure on the surface and pearlite-ferrite structures in the core (Fig. 2, bottom).

\section{Perform Hardness Test}

Because the heat-treated steel contained dense, 1-2 $\mathrm{mm}$ wide martensitic structure on the surface, two hardness tests were conducted to measure the hardness of the steel at various core depths: (a) A longitudinal HV test was performed in a direction parallel to the steel and (b) an HL test was conducted in a direction perpendicular to the steel. Figure 3 illustrates the hardness test of the steel conducted at diverse locations; the left image shows the HV test method and the right image shows the HL test method. To minimize the number of tests conducted while ensuring the reliability of the experimental data, the test reliability and precision range were first set to determine the number of tests to be conducted for related tests. In general practice, the acceptable reliability and tolerance limits are 95 and $\pm 5 \%$, respectively. Therefore, in this study, to determine the number of tests to be conducted, hardness tests were conducted 10-15 times to obtain the mean and standard deviation.

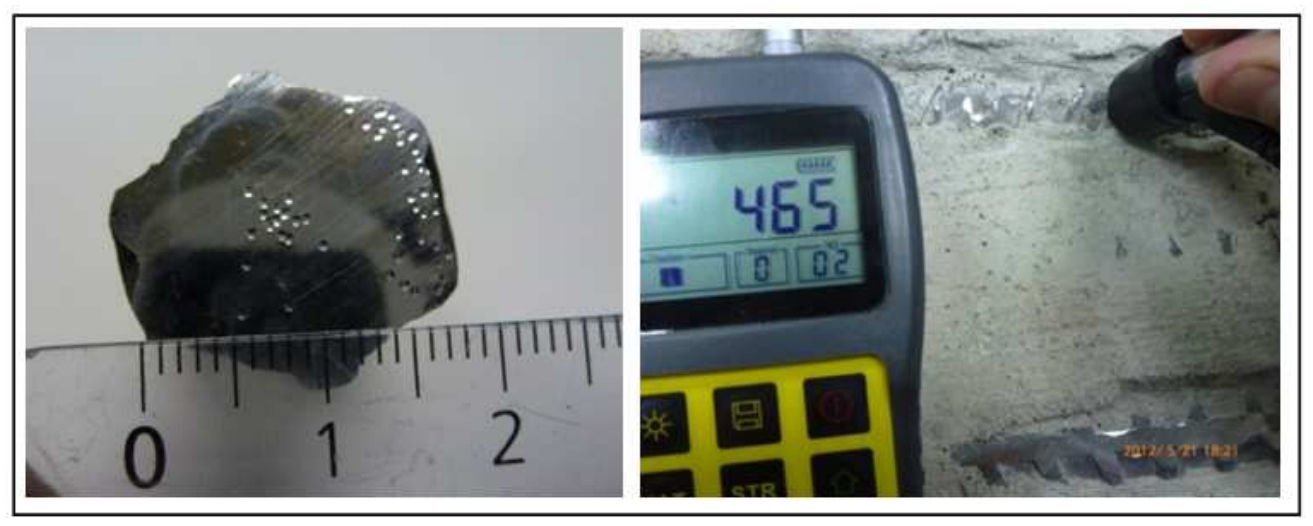

Fig. 3. Hardness tests for steel of varying thickness (left: HV test; right: HL test) 


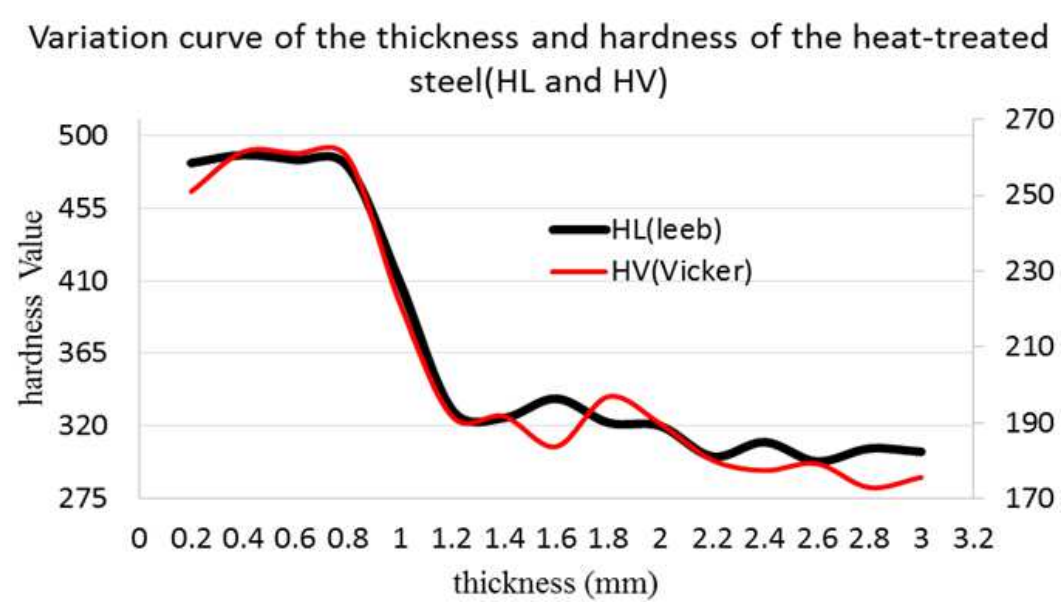

Fig. 4. Variation curve of the thickness and hardness of the heat-treated steel (HL and HV)

Subsequently, the ideal number of tests were determined using the required reliability and permissible error limit and they were 7 and 9 for the HL and HV tests, respectively. Therefore, nine hardness measurements were obtained for each thickness level. Figure 4 illustrates the thicknesshardness variation curve of the heat-treated steel; the horizontal and vertical axes represent the depth and hardness, respectively.

\section{Interpreting the Experiment Results}

As depicted in Fig. 4, because the longitudinal HV test was performed in a direction parallel to the steel, readings obtained from the edges may have been lowered because of energy dissipation (e.g., at $0.2 \mathrm{~mm}$ away from the edge, the $\mathrm{HV}$ value was $251.0 \mathrm{HV}$; at less than $0.4 \mathrm{~mm}$ away from the ledge, the $\mathrm{HV}$ value was $261.5 \mathrm{HV})$. By contrast, because the HL test was performed on the longitudinal section of the steel, in which the test directions faced the core of the steel, the energy dissipation problem was minimized.

Although the definitions of "hardness" differ between different hardness measurement methods and that the measured values cannot be converted interchangeably, the changes in hardness measured using the two aforementioned methods (Fig. 4) both reflected the properties of heat-treated steel (i.e., hard on the surface and soft in the core). Therefore, despite current regulations accepting the use of only $\mathrm{HV}$, which is applicable only to laboratory tests, the results of the experiment conducted in this study indicate that the nondestructive HL test can also be employed in construction sites and that it can produce similar results.

In this study, the difference in steel hardness between the surface of the steel to $1.0 \mathrm{~mm}$ below the surface of the steel was $39.9 \mathrm{HV}$ ( $82 \mathrm{HL}$ ), which is close to the regulated limit (i.e., $40 \mathrm{HV}$ ). Furthermore, inspections at $1.2 \mathrm{~mm}$ below the steel surface showed a hardness difference of 69.8 HV (158 HL), significantly exceeding the specified value. This finding shows that the heattreated steel can be identified by simply removing the protective layer of concrete and grinding the steel by $1-2$ $\mathrm{mm}$, a process that is not expected to create considerable damages to a building's overall structure.

\section{Conclusion and Recommendations}

\section{Test-Related Recommendations}

According to the experiment results, shown in Figure 4, this study recommends the use of the following procedure during onsite steel inspections/evaluation to determine whether the steel used is heat-treated steel:

- On the construction site, confirm the steel location visually or through the use of a metal detector. Knock off the protective layer of the concrete if no steel is exposed

- Polish the surface of the steel (i.e., remove the steel patterns) to be used in the inspection/appraisal

- To measure the HL of the steel, obtain the HL value of the steel surface three times and calculated the mean of the obtained results (label the value as "HL1"; the steel must be firmly fixed in the concrete to ensure that the HL value is not rendered low)

- Polish the surface of the steel in the direction of the core by 1-2 $\mathrm{mm}$ (to remove martensitic structure)

- Obtain the HL value of the grinded surface three times and calculate the corresponding mean (label the value as "HL2")

- Finally, compare the difference between HL1 and HL2. According to the standard listed in CNS560 (Appendix 1), steel with a hardness difference of 
$40 \mathrm{HV}$ between HL1 and HL2 can be considered heat-treated steel. However, because HV values can be measured only in laboratory tests, the corresponding HV values were referenced (Fig. 4). Specifically, when (a) HL1-HL2 $\geq 82 \mathrm{HL}$, the steel can be consideredSD420 heat-treated steel and when (b) HL1-HL2 $<82 \mathrm{HL}$, continue to grind the steel in the direction of the core to determine HL3; when HL1-HL3 $\geq 82$ HL, the steel can be considered heat-treated steel

If HL1-HL3 $<82 \mathrm{HL}$, no conclusive results can be drawn. Although such a result is unfavorable, all testing instruments have limitations and conditions over which they become ineffective. To further identify the steel type, a specimen must be obtained from the site and be tested in a laboratory according to the CNS 2115 (HV test) regulation. Alternatively, a metallographic test can be conducted.

\section{Conclusion}

Because of the inability to obtain work completion data when performing bearing capacity or seismic resistance analyses for existent buildings and because nondestructive testing methods that can be used to identify steel quality (e.g., steel yield strength) or steel type (whether it is heat-treated steel) have not yet been developed, evaluators are regularly required to deduce the bearing capacity or seismic resistance of buildings according to their experience. However, such assumptions often result in distorted results that have a negative effect on the accuracy of subsequent reinforcement operations. In particular, for buildings constructed from heat-treated steel, ensuring that the ductility ratio $(\mathrm{Fu} / \mathrm{Fy})$ meets the regulatory requirements becomes impossible. Therefore, efficient methods for determining the seismic-resistant failure sequence are required. This study proposes a method for identifying heat-treated steel on the construction site, which may be useful information to safety evaluators.

The findings of this study are summarized as follows:

- Although the correlation between steel strength and hardness is influenced by factors such as chemical properties, identifying the type of steel used in RC structures (i.e., whether they are heattreated steel) should remain feasible compared with identifying those used for machinery because of the minimal variations in existing steel types. The experiment results indicated that the hardness test method can be used to determine whether the steel is heat-treated steel

- During the steel-grinding process, we observed that SD420 heat-treated steel demonstrated 1-2 mm-thick martensitic structures on the surface; the martensitic structures were hard and thus difficult to grind. Experienced personnel should therefore be able to notice the difference between heat-treated steel and hot-rolled steel during the grinding process, enabling a reduction in instances of heat-treated steel misuse

- According to the standard listed in CNS560, steel having a hardness difference of $40 \mathrm{HV}$ between the surface and below the surface can be identified as heat-treated steel. In this study, the difference in steel hardness between the surface of the steel and the area1.0 $\mathrm{mm}$ below the surface of the steel was $39.9 \mathrm{HV}(82 \mathrm{HL})$, which is close to the regulated limit (i.e., $40 \mathrm{HV}$ ). This result indicates that when inspecting heat-treated steel on construction sites, only the steel surface must be polished and that the steel need not be damaged to obtain steel specimens

- Currently, the tensile strength method is the commonly used method among engineering personnel to identify of the quality of concrete reinforcement steel. Therefore, the results presented in this study provide a more flexible and reliable method for determining steel type and quality

\section{Author's Contributions}

Shu-Ping Chang: Participated in all experiments, coordinated the data-analysis.

Ming-Chen Chen: Coordinated the data-analysis and contributed to the writing of the manuscript.

Jyh-Dong Lin: Advisor, designed the research plan and organized the study.

\section{Ethics}

This article is original and contains unpublished material. The corresponding author confirms that all of the other authors have read and approved the manuscript and no ethical issues involved.

\section{References}

ACI, 1995. ACI committee 318 building code requirement for structural concrete (ACI 318-95) and commentary (ACI 318R-95) American Concrete Institute. Farmington Hills.

ACI, 2008. ACI 318-08 Standard Building Code. ACI Committee.

ASME Y14.5, 2009. Strength/mechanics of materials menu. American Society Mechanical Engineers Standards.

CALCE, 2012. Material hardness, table of contents. The Center for Advanced Life Cycle Engineering, University of Maryland. 
CER 401-86, 1998. Regulations on the design and construction of concrete-based engineering project explained by the Chinese Institute of civil and hydraulic engineering. Scientific and Technical Publishing Co., Ltd. Civil Engineering Regulation.

Chang, S.P. and C.D. Lin, 2013. Safety analysis of existing structures and steel testing parameters. MSc Thesis, National Central University.

Chen, C.C., S.J. Huang and H.J. Lee, 2000a. Application of controlled-rolling manufactured deformed steel bars on structural seismic design. J. Architecture, 33: 119-131.

Chen, C.C., S.J. Huang and H.R. Lee, $2000 \mathrm{~b}$. Mechanical properties and over-strength factor of steel bars of Taiwan. J. Chinese Institute Civil Hydraulic Eng., 12: 233-238.

Chen, J.L., 2006. Overview of domestic steel industry. Industrial Bank of Taiwan.

CNS, 2005. Article 18.2.5 of civil engineering and architecture, the bureau of standards, metrology and inspection (R.O.C.). Chinese National Standards.

Duan, X.S., X.T. Di, Y. Zhou and L. Tao, 2003. Experimental study on conversion steel leebhardness and tensile strength. Build. Sci., 19: 48-55.
Guan, X.J., X.L. Gu, Q. Chen and W. Zhang, 2004. In situ inspection of strength for steel in existing concrete based on hardness. J. Structural Engineer, 20: 66-69.

Gurchenko, P.S., V.M. Bykov and Y.I. Shumakov, 1990. Surface induction hardening of Minsk Automobile Plant truck final gears. Metal Sci. Heat Treatment, 32: 406-411. DOI: 10.1007/BF01100155

He, C.C., 2000. Mechanisms of rebar materials and CNS requirements. Tung Ho Steel Enterprise Corporation.

Liu, R.L. and M.C. Chen, 2012. On-site non-destructive testing in determining the steel strength of reinforced concrete. MSc Thesis, Chien Hsin University of Science and Technology.

Reed-Hill, R.E. and R. Abbaschian, 2003. Physical Metallurgy Principles. 3rd Edn., International Thomson Publishing Company.

Wang, T.H. and X.J. Guan, 2004. Study on judging study on judging II steel bar tensile strength by Leeb hardness. J. Build. Mater., 7: 432-436. 